\title{
Ion Concentrations And Sources Of Sequential Sampling Of Wet Deposition In Istanbul, Turkey
}

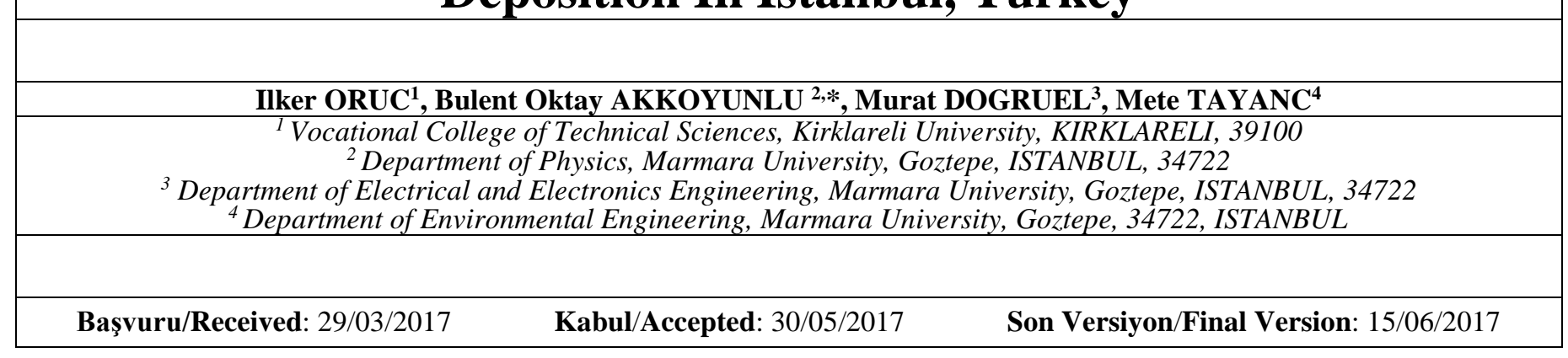

\begin{abstract}
This study presents the relationships between ion concentrations and sources of ions in the precipitation events which happened on a) September the 08th, 2007 b) November the 10th, 2007 and c) December the 05th, 2007. Fortyfour sequential rain samples were collected in three rain events that were sampled in Istanbul-Turkey making use of a sequential rain sampler. Concentration of the main cations $(\mathrm{K}+, \mathrm{Ca} 2+, \mathrm{Na}+$, and $\mathrm{Mg} 2+)$ and main anions (Cl-, SO42-, and NO3-) were analyzed. The ratio of the mean $\mathrm{Ca} 2+(0.85)$ non-sea salt concentration to the mean total concentration led to the conclusion that most of the Ca2+ came from soil. This ratio for SO42- ranged between 0.49 and 0.98 , indicates a possible conclusion that the domestic heating and industrial activities were the main source of this ion.
\end{abstract}

\section{Key Words}

"Aerosol sources, sequential sampling, wet deposition." 


\section{INTRODUCTION}

Atmospheric particles have many sources which are natural and anthropogenic. Natural sources include fine soil blown into the air, coarse particles from soil by wind-blown, sea salts from breaking waves, reactions between natural gaseous emissions, biological material release, and volcanic eruptions. Dust from roads, wind erosion of tilled land and cropland, biomass burning, fossil-fuel combustion, construction, transportation sources and industrial emissions are main anthropogenic sources. Wide processes, which are used to find the sources ions in the precipitation, are non-sea salt (NSS) and enrichment factor (EF) estimations. There are many studies on investigation for researching the sources of the atmospheric constituents. Xu and Gao (2015) proved that sea salt and nss- $\mathrm{SO}_{4}{ }^{2-}$ were the main components of marine aerosols over sampling region, of which high sea salt concentrations were associated with high wind speeds, while high nss- $\mathrm{SO}_{4}{ }^{2-}$ could mainly come from anthropogenic emissions, especially over Asian marginal seas. Huang et al. (2009) claimed that in their study, the influence on precipitation chemistry of sea salts is strong since Guangzhou is located adjacent to the South China Sea. The NSS calculations of ions in the precipitations, in their study, are summarized as follows: The monthly VWM amount of the SSF of $\mathrm{Cl}^{-}$is presented to be 37.8-100\%; equivalent values are 26.6-68.9\% for $\mathrm{Mg}^{2+},<10 \%$ for $\mathrm{K}^{+}$, and just $<2 \%$ for $\mathrm{F}^{-}, \mathrm{SO}_{4}^{2-}$, and $\mathrm{Ca}^{2+}$. According to these data, $\mathrm{Cl}^{-}$in the rain water primarily comes from the sea. Marine source can also be accepted to be the source of the half of the $\mathrm{Mg}^{2+}$ which demonstrates that for the explanation of $\mathrm{Mg}^{2+}$ in the precipitation, an additional source is needed. The SSFs of $\mathrm{Ca}^{2+}, \mathrm{K}^{+}, \mathrm{F}^{-}$, and $\mathrm{SO}_{4}^{2-}$, seems to be very low $(<10 \%)$ which means that there exists another origin besides a marine source. Previous monitoring studies carried out to find the sources of constituents of atmospheric pollutants have profited by NSS estimations (Okay et al., 2002; Sakihama et al., 2008; Budhavant et al., 2010).

The present study is focused on the investigation of sources of the chemical components in the sequential rain events sampled in Istanbul, Turkey using the method of NSS and EF estimations. 44 sequential precipitation samples were collected in the aggregate for the three rain events. It was found $\mathrm{Mg}^{2+}$ came partly from NSS sources (37\%) and $\mathrm{SO}_{4}{ }^{2-}$ almost completely from industrial activities (87\%). $\mathrm{Ca}^{2+}$ and $\mathrm{K}^{+}$are found to have a high mean $\mathrm{EF}$ value. This finding leads to the result that the main source of these ions to be the soil.

\section{MATERIAL AND METHODS}

Goztepe that is the sampling area is on the Asian side of Istanbul (Figure 1). Istanbul that is populated by nearly 15 million people stands as the largest urban settlement in Turkey.

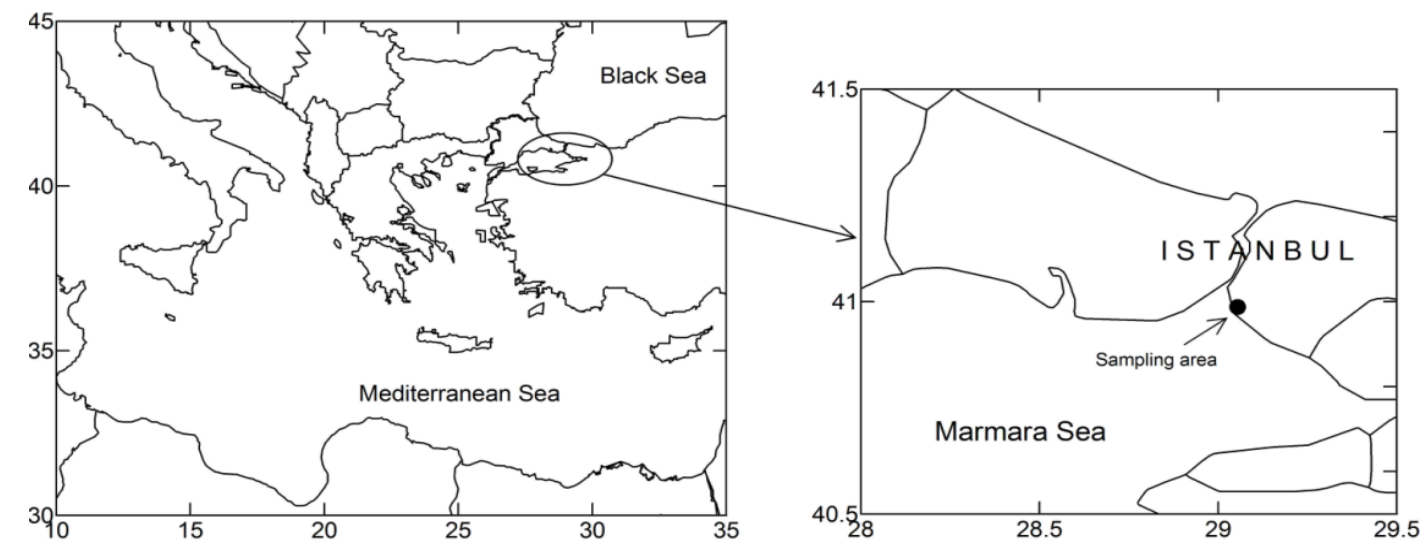

Figure 1. Sampling Site: Goztepe

The EF is a ratio that is usually used to distinguish aerosol sources (Vermette et al., 1988; Singer et al., 1993). This calculation relies on the elemental ratio which is found between ions that are collected in the precipitation or in the atmosphere. When the elemental ratio is compared with a ratio, which is similar, for a reference material, it gives significant information about the elements's source. In this study, the following equation is used in order to calculated EFs for sea water:

$E F=\frac{(x / c)_{\text {precipitation }}}{(x / c)_{\text {reference material }}}$ 
NSS ion concentration formula given by Vermette et al. (1988) was used in order to found the contribution of non natural sources of ions by scavenging processes.

$$
N S S x_{p}=\text { Totalx }_{p}-c_{p}\left(x_{r} / c_{r}\right)
$$

In this equation, $\mathrm{x}$ is the concentration of the ion of interest while $\mathrm{c}$ is the concentration of the reference ion. The subscript $\mathrm{p}$ and $\mathrm{r}$ stand for the ions in the precipitation and reference material, respectively.

To calculate the sea salt ratio, Brewer's (1975) sea surface water concentrations were used as references. We chose $\mathrm{Na}^{+}$as the reference element for sea to calculate the EFs of ions in the rain water.

An automatic sequential rain sampler that was designed and produced in the project carried out with the support of The Scientific and Technological Research Council of Turkey (TUBITAK) was used to collect samples (Akkoyunlu et al., 2008; Akkoyunlu et al., 2011; Akkoyunlu et al., 2013). Sequential sampler device has a polyethylene funnel of $0.28 \mathrm{~m}^{2}$ with circular area and 12 polyethylene cups of $200 \mathrm{~cm}^{3}$ volume mounted on a sampler body. Precipitation sampling caps was taken from the sequential rain sampler body that they were attached to and brought to the laboratory prior to filtering of the samples and storing in pre-cleaned polyethylene bottles in the refrigerator at $4{ }^{\circ} \mathrm{C}$ before the process of chemical analysis.

$\mathrm{K}^{+}, \mathrm{Ca}^{2+}, \mathrm{Na}^{+}$, and $\mathrm{Mg}^{2+}$ concentrations were measured using an Hitachi-180-80 atomic absorption spectrophotometer. $\mathrm{Cl}^{-}, \mathrm{SO}_{4}{ }^{2-}$, and $\mathrm{NO}_{3}{ }^{-}$concentrations were analyzed by a high performance Dionex model 4001 ion chromatography.

\section{SOURCES OF THE IONS}

Equation 1 has been used to calculate the mean EFs of the ions and equation 2 was for obtaining the mean NSS concentrations for all rain events, and these results were depicted in Figure 2. It's been predicted that the rain event with the largest mean EF values in the rain water was on the December the $05^{\text {th }}, 2007$ due to $\mathrm{K}^{+}, \mathrm{Ca}^{2+}$, and $\mathrm{Mg}^{2+}$ were more enriched by soil compared to the other days of the rain event. Higher anthropogenic contribution for $\mathrm{SO}_{4}{ }^{2-}$ during this day of the rain event which leads to higher mean EF values could be probably mentioned to detect the reason. The ratio for $\mathrm{SO}_{4}{ }^{2-}$ ranged between 0.49 and 0.98 . The result that the main source of $\mathrm{SO}_{4}{ }^{2-}$ was the domestic heating and industrial activities might be concluded from these values.

The precipitation events occurred in Istanbul generally have high $\mathrm{SO}_{4}{ }^{2-}$ concentrations mainly originated from the industrial processes and domestic heating. The authors found that $\mathrm{SO}_{4}{ }^{2-}$ was enriched between 1.1 and 150 with respect to the sea (Akkoyunlu and Tayanç, 2003).

Panyakapo and Onchang (2008) indicated that $\mathrm{NH}_{4}{ }^{+}$and $\mathrm{Ca}^{2+}$ were the significant alkaline species for neutralization process. The EFs analysis indicated that $\mathrm{Na}^{+}$and greater part of $\mathrm{Cl}^{-}$were from the sea in this study, while $\mathrm{Ca}^{2+}, \mathrm{Mg}^{2+}, \mathrm{K}^{+}$, and $\mathrm{SO}_{4}^{2-}$ originate from local sources. It was revealed that the crusting as well as anthropogenic activities play an important role in contributing ionic species in wet precipitation by the application of factor analysis. In our study, mean $\mathrm{EF}$ of $\mathrm{Mg}^{2+}$ was calculated as 2.63 , which corresponds to $37 \%$ NSS fraction. It seems that $\mathrm{Mg}^{2+}$ was diluted by sea and concentrated by soil.

The values of mean $\mathrm{Cl}^{-}$and NSS concentration with large difference indicate that NSS has very small amount of partition in the ion. Zhang et al. (2007) found similar values to those of this study. The authors calculated that anthropogenic source fraction of $\mathrm{SO}_{4}{ }^{2-}$ was $98.8 \%$ and crust fraction of $\mathrm{Ca}^{2+}, \mathrm{K}^{+}$, and $\mathrm{Mg}^{2+}$ were $99.4 \%, 97.1 \%, 58.7 \%$, respectively in the 82 precipitation samples collected in southeastern China.
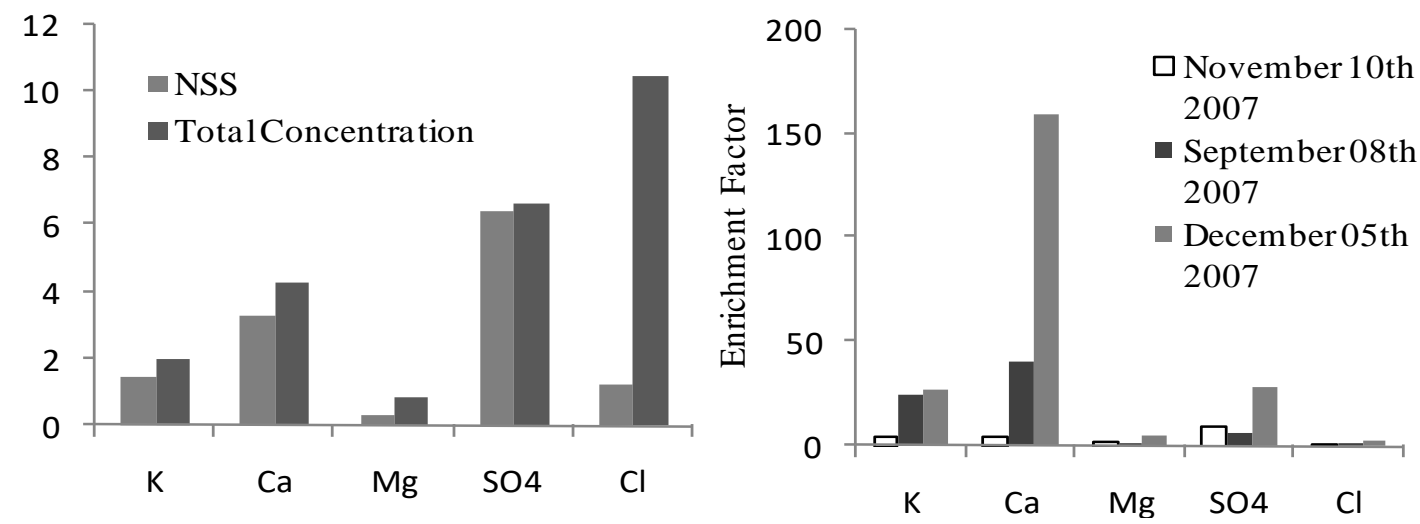

Figure 2. Mean NSS concentrations, total concentrations of ions $\left(\mathrm{mg} \mathrm{L}^{-1}\right)$ and EF values. 
Pearson correlation coefficients of the concentrations of ions for all three cases of rain days were given in Table 1. Maximum correlation coefficient was found 0.74 for the duration of sampling periods between $\mathrm{SO}_{4}{ }^{2-}$ and $\mathrm{NO}_{3}{ }^{-}$that have industrial and domestic sources and in terms of concentration $\mathrm{SO}_{4}{ }^{2-}$ and $\mathrm{NO}_{3}{ }^{-}$generally show similar variability. $\mathrm{Na}^{+}$and $\mathrm{Cl}^{-}$is thought to be originated from sea as the same source. Correlation between them was calculated to be a second pick value as 0.71 . $\mathrm{SO}_{4}{ }^{2-}$ has high or moderate correlation with other ions such as $\mathrm{K}^{+}, \mathrm{Ca}^{2+}, \mathrm{Mg}^{2+}$ which exist in the main soil wind-blown dust particles.

Nevertheless, no correlation between those of other ions and NSS concentration of $\mathrm{SO}_{4}{ }^{2-}$ was found. It refers to the conclusion that $\mathrm{SO}_{4}{ }^{2-}$ which was also thought as anthropogenic sources has different variability than the variability of other ions for duration of rain events.

Topçu et al. (2002) found similar results to the findings of this study. As an example, the authors calculated the correlation coefficient between $\mathrm{SO}_{4}{ }^{2-}$ and $\mathrm{NO}_{3}{ }^{-}$as 0.92 and the correlation coefficients of $\mathrm{Na}^{+}$with $\mathrm{Cl}^{-}$and $\mathrm{Mg}^{2+}$ as 0.77 and 0.54 , respectively in the summer season, in Ankara, Turkey. Cheng et al. (2011) found that $\mathrm{SO}_{4}{ }^{2-}$ and $\mathrm{NO}_{3}{ }^{-}$anions were highly correlated. It was found out that between these ions, the correlation coefficient was 0.7151 .

Table 1. Pearson correlation coefficients between the overall concentrations of ions.

\begin{tabular}{|l|l|l|l|l|l|l|l|}
\hline & $\mathrm{Na}^{+}$ & $\mathrm{K}^{+}$ & $\mathrm{Ca}^{2+}$ & $\mathrm{Mg}^{2+}$ & $\mathrm{NO}_{3}{ }^{-}$ & $\mathbf{S O}_{4}{ }^{2-}$ & $\mathrm{Cl}^{-}$ \\
\hline $\mathrm{Na}^{+}$ & 1 & 0.70 & 0.37 & 0.72 & 0.43 & 0.56 & 0.71 \\
\hline $\mathrm{K}^{+}$ & & 1 & 0.24 & 0.24 & 0.16 & 0.41 & 0.66 \\
\hline $\mathrm{Ca}^{2+}$ & & & 1 & 0.36 & - & 0.04 & 0.72 \\
\hline $\mathrm{Mg}^{2+}$ & & & & 1 & 0.38 & 0.50 & 0.60 \\
\hline $\mathrm{NO}_{3}{ }^{-}$ & & & & & 1 & 0.74 & 0.23 \\
\hline $\mathbf{S O}_{4}{ }^{2-}$ & & & & & & 1 & 0.23 \\
\hline $\mathrm{Cl}^{-}$ & & & & & & & 1 \\
\hline
\end{tabular}

The total concentrations which were described previously in the formula 2 and the reduction as a mean percentage of the NSS concentrations were indicated in Table 2. The decrease of concentrations during the initial stages as a percentage can be ordered in a descending order as $\mathrm{K}^{+}>\mathrm{Cl}^{-}>\mathrm{Na}^{+}>\mathrm{Mg}^{2+}>\mathrm{Ca}^{2+}>\mathrm{NO}_{3}{ }^{-}>\mathrm{SO}_{4}{ }^{2-}$ and descending order of $\mathrm{NSS}$ concentrations as $\mathrm{K}^{+}>\mathrm{Mg}^{2+}>$ $\mathrm{Ca}^{2+}>\mathrm{SO}_{4}{ }^{2-}>\mathrm{Cl}^{-}$in Table 2 .

Fine particles of anthropogenic origin which contains $\mathrm{SO}_{4}{ }^{2-}$ and $\mathrm{NO}_{3}{ }^{-}$are formed by gas-to-particle processes and their scavenging efficiency is much smaller than those of coarse particles. Due to the fact that rain drops are more efficient at scavenging the large particles and coarse mode of aerosols than fine particles. In comparison with the $\mathrm{NO}_{3}{ }^{-}, \mathrm{SO}_{4}{ }^{2-}$ ions which exist as fine particles, more significant reduction of $\mathrm{K}^{+}, \mathrm{Cl}^{-}, \mathrm{Na}^{+}, \mathrm{Mg}^{2+}, \mathrm{Ca}^{2+}$ ions was found. It was found $\mathrm{Mg}^{2+}$ came partly from NSS sources (37\%) and $\mathrm{SO}_{4}{ }^{2-}$ almost completely from industrial activities (87\%). There was no reduction of NSS concentrations of $\mathrm{Mg}^{2+}$ and $\mathrm{SO}_{4}{ }^{2-}$ though other ions has different behaviors. This could be attributed to the possibility that the $\mathrm{Mg}^{2+}$ and $\mathrm{SO}_{4}{ }^{2-}$ originated from NSS have undergone to similar scavenging effects during these precipitation events. Mean reduction of total and NSS concentration of all ions were calculated as $54.7 \%$ and $43.6 \%$, respectively. 
Table 2. Reduction as a percentage of the NSS and total concentrations.

\begin{tabular}{|l|l|l|l|l|l|l|l|}
\hline & $\mathbf{N a}^{+}$ & $\mathbf{K}^{+}$ & $\mathbf{C a}^{2+}$ & $\mathbf{M g}^{2+}$ & $\mathbf{N O}_{3}{ }^{-}$ & $\mathbf{S O}_{4}{ }^{2-}$ & $\mathbf{C l}^{-}$ \\
\hline Total concentration & 60.7 & 82.1 & 46.4 & 53.5 & 34.8 & 30.5 & 74.6 \\
\hline NSS concentration & - & 63.6 & 41.0 & 55.2 & - & 35.5 & 22.8 \\
\hline
\end{tabular}

\section{SUMMARY AND CONCLUSIONS}

Samples of sequential rains were collected in three rain events for the purpose of investigation of the ion concentrations and the sources of ions. During the beginning stages of each rain event, concentrations of nearly all of the ions decreased. The ratio of mean concentration for all ions sampled on the initial stages to that of the final stages of the rain events were calculated. The results of the rain events were found on September the 08th, 2007 as 1.30, on November the 10th, 2007 as 2.29, and on December the 05 th, 2007 as 2 . The decrease of concentrations during the initial stages was sorted in a descending order as $\mathrm{K}+>\mathrm{Cl}->\mathrm{Na}+>\mathrm{Mg} 2+>$ $\mathrm{Ca} 2+>\mathrm{NO} 3->\mathrm{SO} 42-$. This indicated that $\mathrm{K}+, \mathrm{Ca} 2+, \mathrm{Cl}-, \mathrm{Na}+, \mathrm{Mg} 2+$ generally in the coarse particle fraction were more efficiently scavenged than fine particles of anthropogenic origin which formed by gas-to-particle processes and contains SO42- and NO3-. Mean EFs and mean NSS concentrations of the ions were calculated for all rain events for the purpose of finding the sources of ions. It was found that the case of high $\mathrm{EF}$ for SO42- and high correlation between NO3- and SO42- indicates that large amounts of these ions originated in the combustion processes of industrial activities and domestic heating. $\mathrm{Ca} 2+$ and $\mathrm{K}+$ are found to have a high mean EF value. This finding leads to the result that the main source of these ions to be the soil. $\mathrm{EF}$ of $\mathrm{Mg} 2+$ was calculated as 2.63. 63\% of total amount of $\mathrm{Mg} 2+$ originated from sea. Sea might be the mutual source for the $\mathrm{Na}+\mathrm{Cl}-$, and $\mathrm{Mg} 2+$ due to the high correlation coefficients among them.

\section{ACKNOWLEDGEMENT}

Marmara University Scientific Research Project Commission (BAPKO) and TUBITAK financially supported this work with project no FEN-BGS-120707-0153 and 109R022, respectively.

\section{REFERENCES}

Akkoyunlu, B.O., \& Tayanç, M. (2003). Analyses of wet and bulk deposition in four different regions of Istanbul, Turkey. Atmospheric Environment, 37(25): 3571-3579. Doi:10.1016/S1352-2310(03)00349-2

Akkoyunlu, B.O., Tayanc, M., Dogruel, M., \& Oruc, I. (2008). Design and manufacture of an automatic sequential rain sampler: Testing with sub-events. SGEM 2008: 8th International Scientific Conference on Modern Management of Mine Producing, Geology and Environmental Protection, June 16-20, Sofia- Bulgaria, Volume 1, 637-643. ISBN: 954-918181-2

Akkoyunlu, B.O., Oruc, I., \& Tayanc, M. (2011). The Chemistry of Wet Deposition Flux in Istanbul, Turkey. 11th International Multidisciplinary Scientific GeoConference, (SGEM 2011), 19-25 June, Albena-Bulgaria, Volume II, 1255-1262. Doi: 10.5593/SGEM2011/S17.119

Akkoyunlu, B.O., Dogruel, M., Tayanc, M., \& Oruc, I. (2013). Design and construction of a computer controlled automatic sequential rain sampler. Biotechnology \& Biotechnological Equipment, 27(3): 3890-3895. Doi: 10.5504/BBEQ.2013.0016

Brewer, P.G. (1975). Minor elements in seawater. Pp. 415-491. In: Riley J.P., \& Skirrow G. (eds). Chemical Oceanography, Academic Press, London: 2nd Edn. Volume 1. ISBN: 0-12-588601-2

Budhavant, K.B., Rao, P. S. P., Safai, P. D., Gawhane, R. D., \& Raju, M. P. (2010). Chemistry of rainwater and aerosols over Bay of Bengal during CTCZ program. Journal of Atmospheric Chemistry, 65(2): 171-183. Doi: 10.1007/s10874-011-9187-0

Cheng, Y., Liu, Y., Huo, M., Sun, Q., Wang, H., Chen, Z., \& Bai, Y. (2011). Chemical characteristics of precipitation at Nanping Mangdang Mountain in eastern China during spring. Journal of Environmental Sciences, 23(8): 1350-1358. Doi: 10.1016/S10010742(10)60560-8 
Huang, D.Y., Xu, Y.G., Peng, P., Zhang, H.H., \& Lan, J.B. (2009). Chemical composition and seasonal variation of acid deposition in Guangzhou, South China: Comparison with precipitation in other major Chinese cities. Environmental Pollution, $157(1)$ : $35-41$. Doi: 10.1016/j.envpol.2008.08.001

Okay, C., Akkoyunlu, B.O., \& Tayanç, M. (2002). Composition of wet deposition in Kaynarca, Turkey. Environmental Pollution, 118(3): 401-410. Doi: 10.1016/S0269-7491(01)00292-5

Panyakapo, M., \& Onchang, R. (2008). A four-year investigation on wet deposition in western Thailand. Journal of Environmental Sciences, 20(4): 441-448. Doi: 10.1016/S1001-0742(08)62077-X

Sakihama, H., Ishiki, M., \& Tokuyama, A. (2008). Chemical characteristics of precipitation in Okinawa Island, Japan. Atmospheric Environment, 42(10): 2320-2335. Doi: 10.1016/j.atmosenv.2007.12.026

Singer, A., Shamay, Y., Fried, M., \& Ganor, E. (1993). Acid rain on Mt. Carmel, Israel. Atmospheric Environment, 27(15): 22872293. Doi: 10.1016/0960-1686(93)90398-I

Topçu, S., Incecik, S., \& Atimtay, A.T. (2002). Chemical composition of rainwater at EMEP station in Ankara, Turkey. Atmospheric Research, 65(1): 77-92. Doi: 10.1016/S0169-8095(02)00072-8

Vermette, S.J., Drake, J.J., \& Landsberger, S. (1988). Intra-urban precipitation quality: Hamilton, Canada. Water, Air, and Soil Pollution, 38(1): 37-53. Doi: 10.1007/BF00279584

$\mathrm{Xu}, \mathrm{G}$. , \& Gao Y. (2015). Characterization of marine aerosols and precipitation through shipboard observations on the transect between $31^{\circ} \mathrm{N}-32^{\circ} \mathrm{S}$ in the West Pacific. Atmospheric Pollution Research, 6(1): 154-161. Doi: 10.5094/APR.2015.018

Zhang, M., Wang, S., Wu, F., Yuan, X., \& Zhang, Y. (2007). Chemical compositions of wet precipitation and anthropogenic influences at a developing urban site in southeastern China. Atmospheric Research, 84(4): 311-322. Doi: 10.1016/j.atmosres.2006.09.003 